\title{
John McGahern and the temporalities of modernity
}

\section{Yen-Chi Wu}

\author{
School of English, UCC
}

\begin{abstract}
"This is how one pictures the angel of history. His face is turned toward the past. Where we perceive a chain of events, he sees one single catastrophe which keeps piling wreckage upon wreckage and hurls it in front of his feet. The angel would like to stay, awaken the dead, and make whole what has been smashed. But a storm is blowing from Paradise; it has got caught in his wings with such violence that the angel can no longer close them. The storm irresistibly propels him into the future to which his back is turned, while the pile of debris before him grows skyward. This storm is what we call progress." (Walter Benjamin, "Theses on the Philosophy of History")
\end{abstract}

\section{Introduction}

How does time flow? One might simply answer: from the past to the present and to the future. Indeed, this is perhaps the most common conception of time, which is based on linear progression. In fact, such a conception is so common that one rarely thinks of other possibilities of the temporal movement. When we uncritically apply this idea to history, however, we miss out on the complex flows within culture.

Conventional historicism relies on this linear temporality and perceives history as a "progress" from the primitive to the pre-modern and to the modern. In this regard, lifestyles and practices in the past are simply superseded and "improved" by more progressive modern conditions. The linear conception of time may be innocuous in itself, but conventional historicism has unwittingly created a modern myth in progress, including the dichotomy between tradition and modernity. With the notion of progress, tradition is relegated as old-fashioned, regressive and conservative; while modernity is lauded as enlightening, rational and liberal. But is this progressive modernity so unanimously unquestionable, even in different locations?

Walter Benjamin had pointed out the peculiar violence in the modern myth of progress. In his depiction of the Angel of History, Benjamin sees the angel facing backwards while the forceful wind of progress propels him to move forward; before his eyes are debris of the past that are crushed and scattered in the progression of history. From a postcolonial perspective, Benjamin's critique of historicism and modernity was particularly illuminating. In the colonial era, colonial modernity was used to relegate the colonial subjects as pre-modern so as to justify the colonist's dominance. In the anti-colonial stage, however, the colonized reversed the game by embracing the "pre-modern" features as a prided 
tradition. In the postcolonial society, therefore, the relationship between tradition and modernity was especially fraught, and the violence of progress was particularly palpable.

\section{From traditional to modern Ireland}

In the Irish context, the mid-twentieth century is often regarded as the watershed in which traditional (Catholic, rural) Ireland gave in to modern (liberal, economically-driven) Ireland. In the historicist sense then, traditional Ireland is now gone, replaced by a more progressive modern Ireland. In this vein, how do we assess a modern writer whose novels primarily invest in the rural Ireland of the mid-twentieth century? Is he hopelessly nostalgic, or is he proposing a more refined conception of historicism and modernity by persistent returning to the Irish rural past? John McGahern is such a writer that deserves more critical attention to the complex temporalities embodied in his work. His writing career and his novels register temporal qualities that defy the modern linear progression. My project, foregrounding the issue of temporality in John McGahern's work, examines the writer's relationships to Ireland's past as well as to its modernity.

\section{Three stages of McGahern's novelscircling back to the rural past}

McGahern's writing career spans across half a century, from the early 1960s to the 2000s, and witnesses Ireland's rapid modernisation. His novels are often seen in three stages: the early novels bear strong social critique of the insular rural Ireland; the mid-career novels depart from the rural setting and are more experimental in writing style; the later novels return to the rural Ireland of his childhood but the narrative tones have become gentler.

The social critiques in his early novels subjected McGahern to controversy. His debut novel, The Barracks (1963), enjoyed a general welcoming reception. The novel has an autobiographical undertone. The female protagonist, like McGahern's mother, is diagnosed with breast cancer and seeks to come to terms with her illness and impending death. Her husband, similar to the author's father, is a moody police sergeant capable of violent emotional outburst. McGahern thus scrutinizes the insular rural Ireland, as mirrored in the depressed household.

His second novel, The Dark (1965), probes the touchy issues of domestic and clerical child abuse. The novel famously opens with a detailed scene in which the young protagonist is stripped naked while his father threatens to whip him and causes him to lose bladder control. The sexual undertone in this scene is brought to light later when the father, sharing the bed with his son, caresses the boy to help himself to reach orgasm. To escape from his abusive father, the boy seeks a clerical career. Unfortunately, when consulting for advice, the boy is met with a Father who makes improper sexual moves and reminds him of his own father. These patriarchal figures serve as strong social critiques of the insular 
rural Catholic Ireland. The novel was banned by the Irish Censorship Board for contents of indecency and vulgarity. As a consequence, McGahern lost his teaching job.

Stigmatized as a dirty writer for the banning of his book, McGahern was forced to selfexile. His mid-career novels, following his home-leaving, are often set in the big cities of London and Dublin. The themes consequently departed from the author's previous focus on rural Ireland. The Leavetaking (1974) is a semi-autobiographical novel, following the last day of a Catholic schoolteacher before his sacking. The narratives interweave past and present events, giving accounts of the protagonist's becoming a teacher and his year on sabbatical in London where he marries a divorced American woman outside the Church. The marriage is disapproved by the school at his return, and the protagonist is therefore dismissed from his teaching position. Even though Catholic dogmatism still plays a major role, the novel focuses more on the London period when the protagonist tries to sort himself out. The novel thus, as the title suggests, takes leave from the rural Ireland, as McGahern did with his exile.

The Pornographer (1979) is a whimsical yet profoundly philosophical novel that looks at sex, death and art. The protagonist makes his living by writing cheesy pornographies, which are sometimes based on his real life experiences. Accidentally impregnating a woman he does not love, the protagonist struggles to take the responsibility, which he ultimately refuses. This seemingly demoralized man, however, is movingly attentive to his dying aunt in the rural area. The complexity of this pornographer thus showcases the dual sides of a man who is indulged in urban individualism and yet capable of taking moral responsibility in a rural context.

With McGahern's return to County Leitrim with his wife, the diminished rural themes in his mid-career novels resurfaced in his latter ones. His last two novels relocated back to the rural Ireland of his childhood. Different from his early works that carry social critiques of rural Ireland, McGahern's latter novels use gentler narratives that seemingly eulogize the disappearing rural civilization. McGahern's career trajectory thus shows a circling back to where he had begun, but the writer had learned to see the rural world with different eyes.

\section{The strange sense of timelessness}

The latter two novels, in addition to marking McGahern's circling career trajectory, register complex temporal quality in the writing. In fact, McGahern's writing is characteristic of recurring characters and recursive narratives that render his body of work an organic whole. Viewed in its wholeness, McGahern's novels seem to be the author's effort to revise and to hone the same stories over and over again. In his latter two novels, this trope of recurrence and repetition consummates in a sense of strange timelessness.

In his review of Thomas O'Crohan's The Islandman (1929), McGahern praised "the strange 
sense of timelessness" in the memoir. The unit that marks the progression of time is the day. As one day ends, a new day begins. In this way, the memoir registers a sense of repetition and renewal. Moreover, the memoir records the non-modern life of the people in the Great Blasket Islands, which seems to stand outside national history. These features together contribute to the strange timeless quality in the book. Critics often agree that McGahern's latter two novels have achieved similar timeless quality. The progressions of both novels are marked by seasonal changes, rituals and the family members' leaving and homecoming, which eludes the chronological time.

Amongst Women (1990) is a family saga, telling the story of the Morans of Great Meadow. While focusing on one family, the novel also showcases Irish history in the latter half of the twentieth century. The story opens with the Moran girls' attempt to revive the Monaghan Day so as to put life in their weakening father at his old age. The narrative then shifts back to the actual Monaghan Day and follows the children's developments from their adolescence to young adulthood, which account for the main body of the novel. The narrative finally returns to the narrative present and ends with Moran's funeral. The temporal progression thus embodies a circling quality instead of a linear one. The depiction of the Moran's rural homestead, the Great Meadow, as a place where "nothing but the years change" intensifies the strange timeless quality in the novel.

McGahern's last novel, That They May Face the Rising Sun (2002), is an unconventional story without the development of a plot. The novel focuses on the lives of a lakeside community in rural Ireland, reminiscent of McGahern's country house in County Leitrim. The main protagonists are the Ruttledges, a middle-aged couple who returns to the rural Ireland after years of working in London, like McGahern and his wife. The narrative is often interrupted by accounts of their neighbours' backstories, usually provided by the nosy yet charming Jamesie. The recursive narratives are complimented by the theme of repetition and revival. There are nearly identical phrases and paragraphs in the narrative, which contribute to a sense of ritual that marks the passing and renewal of time at the same time. The title of the novel comes from the local funeral ritual, according to which the dead are buried with their heads in the west, so that they may face the rising sun when they awake. This sense of ritual and resurrection also contribute to the timeless quality, as the time passes and returns, defying the linear progression that moves only forward.

In addition to the recursive narratives and the trope of revival, the images of clock also play a significant part in That They May Face the Rising Sun. In Jamesie and Mary's house, there is a wall of pendulum clocks, but these clocks are unsynchronised. When Jamesie's brother Johnny died, they stopped the clocks in respect to the local funeral ritual. After the funeral, Jamesie and Mary hired a clocksmith to rewind the clocks, but there are still two clocks that chimed late. The clocksmith is booked to return for a final adjustment, but the novel ends before his return. It is therefore uncertain if the two unsynchronised clocks would finally catch up with other clocks, or if they would be left alone. The broken rhythm 
carried in this image of unsynchronised clocks neatly represents the strange temporal quality in McGahern's oeuvre. Instead of moving in a linear progression toward modernity, McGahern's novels probed the different temporalities of modernity.

\section{Conclusion}

In view of McGahern's writing career that circles back to the rural Ireland of the midcentury and the timeless quality in his latter novels, McGahern is usually associated with the traditional and older rural culture. The corollary is that McGahern's work has very little to do with Ireland's modern conditions. In fact, McGahern has been accused of being indifferent to Ireland's modernisation. Such an accusation, however, is predicated on the linear temporality and the myth of progress. My projects seeks to re-address this presumption by complicating the dichotomizing traditional/modern figure. Drawing from postcolonial and Marxist theories on modernity and temporality, my research argues that the strange timeless quality in McGahern's novels presents an unsynchronised rhythm that challenges progressive modernity. In thus doing, my project re-assesses McGahern's writing in a more theoretically-informed framework and re-evaluates the cultural significance of rural Ireland in temporal terms.

The author would like to express his gratitude to his supervisors, Professor Claire Connolly and Dr. Heather Laird, who have been most helpful and supportive of this project. Extended gratitude also goes to the Irish Research Council for their generous funding. 